\title{
Thrombus-specific manganese-based "nanobialys" for MR molecular imaging of ruptured plaque
}

\author{
Dipanjan Pan ${ }^{1 *}$, Shelton D Caruthers ${ }^{1}$, Angana SenPan ${ }^{1}$, Anne H Schmieder ${ }^{1}$, Todd A Williams ${ }^{1}$, Michael J Scott ${ }^{1}$, \\ Patrick J Gaffney², Samuel A Wickline', Gregory Lanza ${ }^{1}$ \\ From 15th Annual SCMR Scientific Sessions \\ Orlando, FL, USA. 2-5 February 2012
}

\section{Summary}

Mathematical modeling studies have suggested that nonspherical, disc-shaped nanoparticles may have optimal intravascular flow and homing characteristics. In this study, we report the development of a fibrin-specific high-relaxivity bialy-shaped polymeric nanoparticle using porphyrin-chelated manganese. We anticipate that this agent would be highly effective for molecular imaging of microthrombi in ruptured atherosclerotic plaques.

\section{Background}

Detection of microthrombi within fissures of vulnerable atherosclerotic plaques requires a sensitive molecular imaging contrast agent. Moreover, recent reports based on mathematical modeling suggest that nonspherical, disc-shaped nanoparticles could have improved intravascular flow characteristics, which may improve liganddirected targeting. In light of the concern surrounding the use of gadolinium in patients with severe renal disease, the goal of this research was to develop a nonspherical fibrin-targeted manganese-based molecular imaging agent.

\section{Methods}

A new class of manganese (III)-labeled, a toroidalshaped, vascularly-constrained nanoparticles, "nanobialys (MnNBs)", was designed, synthesized, physically characterized, and evaluated for MR properties. Single slice inversion recovery and multi-echo spin echo sequences were used to calculate the ionic (per metal) and particulate (per particle) relaxivities from 7 serial dilutions of nanobialys at $1.5 \mathrm{~T}$ and $25^{\circ} \mathrm{C}$. Fibrin clots supported on silk suture suspended in PBS were targeted with MnNB or control (non-paramagnetic) NB to the fibrin clots with avidin-biotin interactions and fibrin-specific antibodies (NIB5F3). Magnetic resonance images (3T) of the clots were acquired using T1weighted gradient echo techniques.

\section{Results}

Mn-nano-bialys were $190 \mathrm{~nm} \pm 5 \mathrm{~nm}$ with polydispersity of $0.26 \pm 0.01$. (Fig 1) In the hydrated state, Manganese content was $25.6 \pm 03 \mu \mathrm{g} / \mathrm{mL}$ by ICP OES, i.e., 165,000 $\mathrm{Mn}(\mathrm{III})$ per nanobialy. The particulate relaxivities of the MnNB were high, $r 1=612,307 \pm 7213$ and $r 2=866,989$ \pm 10704 ( $\bullet \bullet \mathrm{mmol}$ [nanobialy]) -1 measured at $1.5 \mathrm{~T}\left(25^{\circ}\right.$ C), with ionic $\mathrm{r} 1$ and $\mathrm{r} 2$ relaxivities of $3.7 \pm 1.1$ and 5.2 $\pm 1.1(\mathrm{~s} \bullet \mathrm{mmol}[\mathrm{Mn}])-1$, respectively. MR imaging of MnNB targeted to fibrin clot phantoms showed clear contrast enhancement, while control clots had no $(\mathrm{p}<0.05)$ contrast change (Fig 2).

\section{Conclusions}

Fibrin-specific MnNBs are a novel, high relaxivity, nongadolinium, molecular imaging agent that offers a sensitive noninvasive MR imaging approach for diagnosis of ruptured atherosclerotic plaques.

\section{Funding}

$\mathrm{NIH}$.

\section{Author details}

${ }^{1}$ Medicine, Washington University, Saint Louis, MO, USA. ${ }^{2}$ Surgery, Saint Thomas', London, UK.

Published: 1 February 2012

${ }^{1}$ Medicine, Washington University, Saint Louis, MO, USA

Full list of author information is available at the end of the article

C 2012 Pan et al; licensee BioMed Central Ltd. This is an open access article distributed under the terms of the Creative Commons 


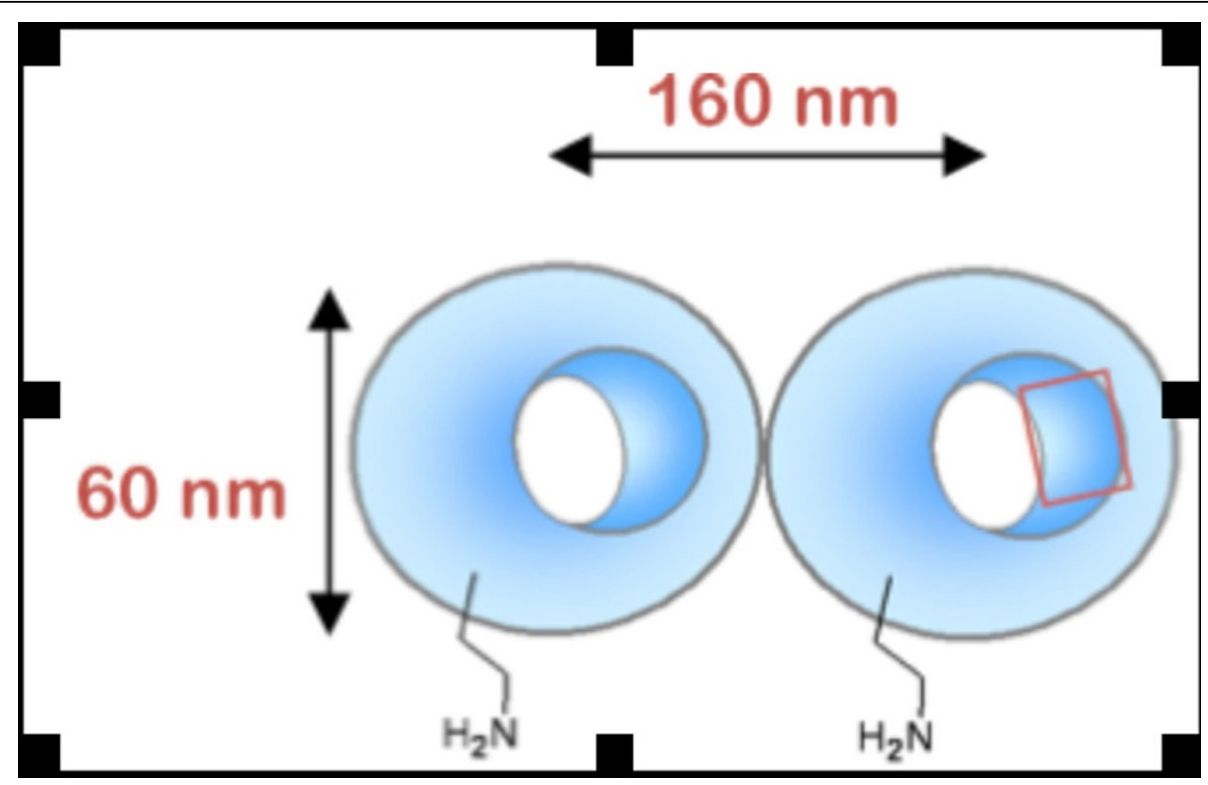

Figure 1 Cartoon depiction of NanoBialy based on hydrodynamic dynamic light scattering measurements. The particles appear biconcave or bialy-shaped, much like erythrocytes. The high surface-to-volume aspect of the particle is densely decorated with Mn-porphryn chelates.
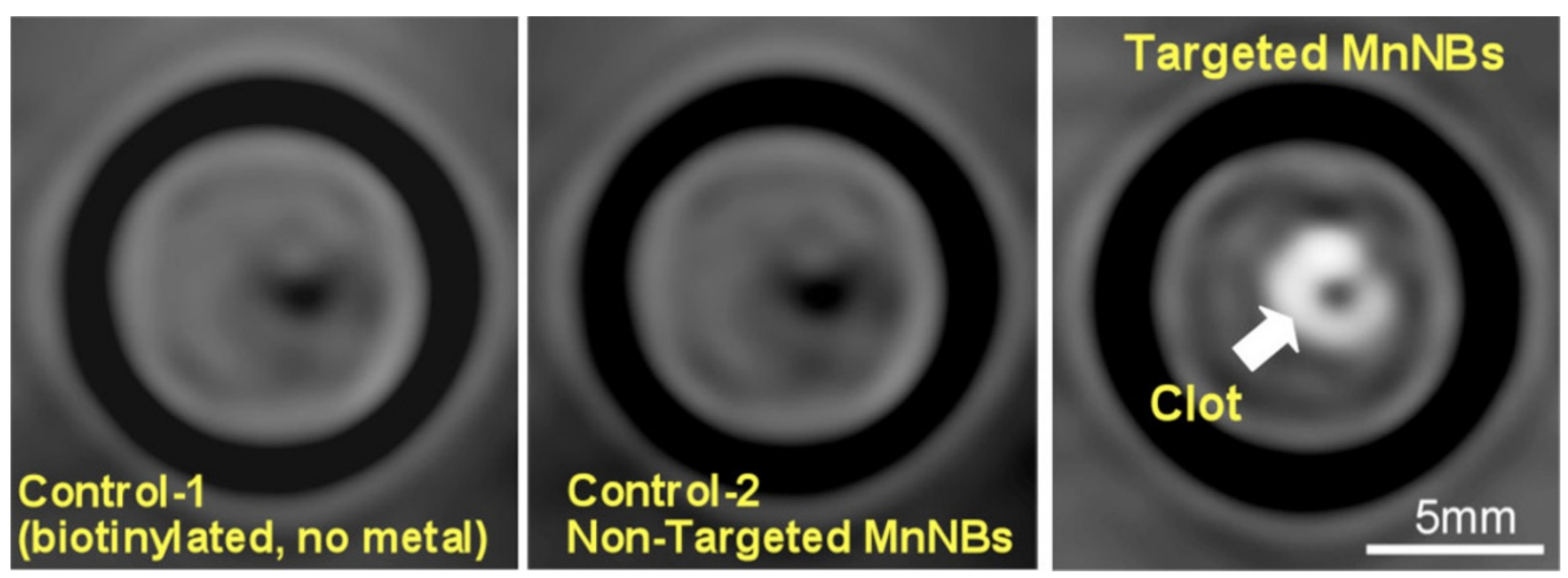

Figure 2 MRI images of fibrin-targeted nanobialys (right) or control nanoparticles bound to cylindrical plasma clots measured at 3.0T. The ionic and particulate $r 1$ relaxivities of serially diluted nanobialys at 3.0T were $3.1 \pm 1.1$ ( $\bullet \bullet \mathrm{mmol}[\mathrm{Mn}])-1$ and 512,863 \pm 8408 ( $\bullet \bullet \mathrm{mmol}[\mathrm{nanobialy]}$ )1 respectively.

doi:10.1186/1532-429X-14-S1-P136

Cite this article as: Pan et al:: Thrombus-specific manganese-based

"nanobialys" for MR molecular imaging of ruptured plaque. Journal of

Cardiovascular Magnetic Resonance 2012 14(Suppl 1):P136.

\section{Submit your next manuscript to BioMed Central} and take full advantage of:

- Convenient online submission

- Thorough peer review

- No space constraints or color figure charges

- Immediate publication on acceptance

- Inclusion in PubMed, CAS, Scopus and Google Scholar

- Research which is freely available for redistribution 